\title{
MESTRADO PROFISSIONAL EM ENFERMAGEM - UM NOVO MOMENTO PARA A PROFISSÃO NO BRASIL
}

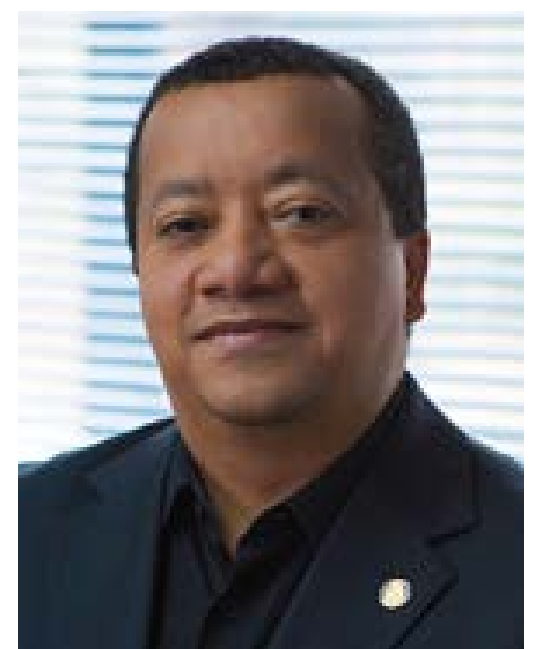

Manoel Carlos Neri da Silva

Presidente do Cofen
O Programa de pósgraduação em Enfermagem (Profen), idealizado e financiado pelo Conselho Federal de Enfermagem (Cofen), chegou para impulsionar e mudar a formação de Enfermeiros mestres para o desenvolvimento da Ciência e da profissão de Enfermagem no Brasil. Em parceria com a Coordenação de Aperfeiçoamento de Pessoal de Nível Superior (Capes/ MEC), o programa foi lançado em 2016, abrindo uma nova perspectiva de qualificação profissional para enfermeiros. 0 programa contribui para implementação, de forma mais eficaz e efetiva, da Sistematização da Assistência de Enfermagem e do Processo de Enfermagem na Rede de Atenção à Saúde do Sistema Único de Saúde (SUS).

Conseguimos colocar em prática o maior programa de mestrado profissional do país, uma gigantesca e arrojada estratégia do Cofen. Em parceria com a Capes, lançamos editais para fomento dos mestrados profissionais, ampliando chances de crescimento para enfermeiros devidamente inseridos em seus contextos de trabalho e contribuindo para disparar processos de transformação em suas práticas no SUS.

Observando o descompasso entre a mão-de-obra qualificada já existente e as necessidades da Saúde Coletiva, o Cofen decidiu apoiar os programas de pós-graduação com financiamento de custeio para a oferta de Mestrado Profissional em Enfermagem que em 5 anos serão investidos 13 milhões de reais. O objetivo não foi somente de atender parte da demanda reprimida por qualificação dos enfermeiros assistenciais, mas, sobretudo, contribuir para a transformação da assistência em Enfermagem. Como órgão que tem a finalidade de zelar pelo bom exercício profissional, foi uma honra gerir um projeto de tal magnitude e com impacto real no quantitativo de profissionais enfermeiros a serem titulados, entregando à sociedade cerca de 500 profissionais com mestrado em cinco anos.
A iniciativa consolidou-se em um projeto amplo que busca otimizar a assistência da enfermagem à população brasileira nos serviços de saúde. No primeiro edital, viabilizamos 140 vagas em 16 programas de mestrado profissional, com amplo impacto na prática da Enfermagem. Os primeiros resultados já começaram a ser vistos em diversos projetos desenvolvidos Brasil a fora, não deixando dúvidas de que essa é uma nova etapa que se inicia para a valorização da Enfermagem brasileira. Do total de profissionais selecionados no primeiro edital, muitos já defenderam suas dissertações no programa, e as dissertações apresentadas motivaram a produção desse número especial da Revista Enfermagem em Foco, trazendo as pesquisas inéditas, realizadas pelos discentes do programa.

No mês de novembro de 2019 foi lançado o segundo edital que ofertará mais 180 vagas e uma nova linha de pesquisa. O Cofen aprovou a inserção da modalidade de mestrado com oferta de vagas "fora de sede" e ampliação das linhas de pesquisa, inserindo a área Gestão de Enfermagem no escopo do Acordo de Cooperação Técnica firmado entre Cofen e Capes. Esta mudança é uma resposta às dificuldades dos enfermeiros da rede de atenção à saúde nas regiões prioritárias de se qualificarem em nível de Mestrado, dada a inexistência ou insuficiência dessa modalidade de formação nos seus estados, associada às questões geográficas, tanto da grande distância de centros com maior disponibilidade de vagas, quanto da dificuldade de arcar com os elevados custos pessoais e sociais envolvidos no deslocamento até as regiões que concentram as pós-graduações stricto sensu em Enfermagem.

Sem dúvida, cursar um mestrado profissional em universidades renomadas, que capacitam os enfermeiros com a melhor instrumentalização teórica, tecnológica e científica, representa uma significativa valorização dos profissionais.

Neste número foram selecionados vinte artigos oriundos de pesquisas desenvolvidas nestes Programas voltados à Sistematização da Assistência de Enfermagem em diferentes aspectos. Espera-se que estes possam, além de divulgar esta produção, servir de incentivo aos enfermeiros do país e contribuir para um cuidado de qualidade.

Agradeço aos autores que produziram para esta publicação, manuscritos inéditos e de grande qualidade e aos editores da Revista Enfermagem em Foco por tornar essa publicação uma realidade e, ainda a dedico a todos os profissionais de Enfermagem do Brasil 